\title{
A influência das áreas verdes nos serviços públicos de saúde na cidade de Mandaguari, Paraná, Brasil
}

\section{The influence of green areas in health public services in the city of Mandaguari, Paraná, Brazil}

\author{
Nestor Alexandre Perehouskei ${ }^{1}$, Bruno Luiz Domingos De Angelis ${ }^{2}$.
}

1. Doutorando em Geografia da Universidade Estadual de Maringá (UEM), Paraná, Brasil. 2. Programa de Pós-Graduação em Geografia da Universidade Estadual de Maringá (UEM), Centro de Ciências Agrárias, Departamento de Agronomia, Paraná, Brasil.

\section{Resumo}

Objetivos: o presente trabalho consiste no desenvolvimento de pesquisa sobre a importância das áreas verdes urbanas no contexto dos serviços públicos de saúde na Cidade de Mandaguari, Paraná. Métodos: inicialmente, foram utilizados os dados de Autorização de Internação Hospitalar (AIH) no período de 2000 a 2010, disponibilizados pelo banco de dados DATASUS, buscando identificar os problemas de saúde de maior ocorrência, cujos resultados apontaram para as doenças do aparelho respiratório e circulatório, que pressupõem em seus tratamentos, a realização de atividades físicas que podem ser realizadas com aproveitamento para a saúde, em espaços livres públicos. Resultados: a partir de pesquisa investigativa, com a aplicação de questionário junto a 362 usuários, verificou-se que, em relação aos espaços públicos, as pessoas entrevistadas reconhecem a importância das áreas verdes para a melhoria da qualidade de vida. Dos 362 usuários, 357 (98,6\%) consideram que as áreas verdes oferecem ar puro, limpo e saudável, sendo um ótimo espaço para atividades físicas, recreação e outras. Cinco usuários (1,3\%) do universo amostrado não consideram a contribuição das áreas verdes para a saúde, pela desinformação, ou mesmo, a dificuldade em associar os temas. Conclusão: nessa perspectiva, o conceito de território, no âmbito do setor de saúde, passa a adotar em seu próprio conceito a inclusão das potencialidades provindas da presença das áreas verdes urbanas, que contribuem para as boas condições de vida das comunidades envolvidas.

Palavras-chave: Saúde. Saúde Ambiental. Características Culturais.

\begin{abstract}
Objective: This work is the development of some research on the importance of urban green areas in the context of public health services in the City of Mandaguari, Paraná. Methodology: Initially, the data of the Hospital Admission Authorization (HAA) was used in the period from 2000 to 2010, which was provided by the database DATASUS, aiming at identifying the most frequent health problems, whose results pointed to the diseases of the respiratory and circulatory systems, which require in their treatment, the physical activities that can be performed in the benefit of health in free public spaced. Results: From an investigative research, under the application of a questionnaire to 362 users, it was found that in relation to the public spaces, the interviewed people recognize the importance of green areas to improve their quality of life. 357 out of 362 users (98.6\%) consider that the green areas provide some pure, clean and healthy air, and provide a great space for physical activities, recreation and others. Five users $(1.3 \%)$ of the population sampled did not consider the contribution of the green areas for health, due to of their lack of information or even the difficulty in associating these issues. Conclusions: Under this perspective, the concept of territory, in relation to the healthcare sector, adopts in its own concept the inclusion of the potentialities that come from the presence of the urban green areas, which contribute to some good living conditions of the communities involved.
\end{abstract}

Keywords: Health. Environmental Health. Cultural Characteristics.

\section{INTRODUÇÃO}

Este trabalho é reflexo de um aprendizado, tanto nos estudos de Geografia, quanto na área das Ciências da Saúde. Pode-se considerar, também, fruto de um trabalho desenvolvido na área municipal dos serviços de saúde, realizados há mais de uma década, considerando, inclusive, o atendimento pessoal junto aos usuários do Sistema Único de Saúde (SUS), focando-se no contato direto com as necessidades da população, em contraste com o descaso do poder público em organizar de forma eficaz os serviços para atender a essas demandas.

Conflito de interesses: Todos os autores declaram não haver qualquer tipo de conflito de interesse existente durante o desenvolvimento do estudo. Correspondência: Nestor Alexandre Perehouskei. Programa de Pós-Graduação em Geografia da Universidade Estadual de Maringá. E-mail: nestorap@pop.com.br Recebido em 24 Abr 2013; Revisado em 19 Mai 2014; Aceito em 5 de Jun 2014. 
No decorrer dessa trajetória utilizou-se dos conhecimentos geográficos, objetivando trabalhar o planejamento dos serviços de saúde e o planejamento urbano, especificamente em áreas verdes urbanas, na perspectiva territorial. Estudos no âmbito da Geografia vêm se utilizando das temáticas espacial e territorial em suas discussões, e um desses enfoques são os estudos dos territórios sanitários, defendidos pela política pública Pacto em Saúde ${ }^{1}$, que auxilia o desenvolvimento desses estudos dentro da realidade das regiões, ou seja, os territórios sanitários não devem ser divididos a partir de critérios administrativos, e sim, a partir das realidades locais e regionais de suas comunidades.

Entre as novas estratégias para o redirecionamento dos serviços de saúde, especialmente no planejamento da mesma, os especialistas nesta área têm enfatizado a interferência significativa do território em suas ações.

Nesta perspectiva, torna-se imprescindível inserir nos territórios áreas de abrangência das Unidades Básicas de Saúde (UBS) na lógica dos territórios sanitários, por serem áreas de atuação dos profissionais de saúde diretamente articuladas com as comunidades, e, como tal, experienciadas a partir de realidades vividas nos territórios. Essa proposta inclui a atuação da Estratégia de Saúde da Família (ESF) que pressupõe um atendimento domiciliar junto às famílias cadastradas, com a atuação de uma equipe multidisciplinar, chamada Equipe Saúde da Família, composta por médico, enfermeiro, auxiliar de enfermagem e, no mínimo, quatro Agentes Comunitários de Saúde (ACS).

A cidade de Mandaguari, com cerca de 33.000 habitantes, é composta por seis ESF, sendo cada UBS, composta por uma equipe e, atualmente, com uma cobertura de atendimento a cerca de $70 \%$ da população adscrita.

Os critérios para estabelecer os limites dessas áreas são os mais variados e, por isso, poucos atingem o objetivo.

Nesta perspectiva ${ }^{2}$ foram estudados os critérios para estabelecer a delimitação das áreas de abrangência dos Núcleos Integrados de Saúde (NIS) do município de Maringá, no Estado do Paraná, considerando as opiniões emitidas pelas Equipes Saúde da Família (ESF).

A partir deste estudo, estruturaram-se alguns parâmetros para a delimitação dos recortes territoriais: fluxos de população na busca de atendimento junto aos serviços de saúde; distribuição de equipamentos urbanos no território; acessibilidade considerando os meios de transporte e barreiras geográficas existentes nos trajetos até os NIS; distância entre a moradia e os serviços de saúde, e, também, a estrutura dos serviços oferecidos pelas UBS às comunidades usuárias.

A adoção de alguns critérios estabelecidos nessa pesquisa para o planejamento dos serviços contribuiu para minimizar aspectos de exclusão social nos atendimentos em saúde, pois, muitas famílias que não recebiam auxílio domiciliar passaram a receber o atendimento.

Ainda ${ }^{3}$ estudaram a percepção das comunidades usuárias dos serviços públicos de saúde, nos bairros Jardim Universo e Jardim Pinheiros do município de Maringá, Estado do Paraná, com relação à área de abrangência de seus NIS, verificando que a divisão de áreas previamente estabelecida pelo serviço de planejamento da Secretaria Municipal de Saúde, sofre importantes distorções quando comparadas com a divisão de áreas estabelecida pelas comunidades usuárias, constatando, assim, aspectos de exclusão social nos atendimentos domiciliares em saúde.

Por que, além de verificar os aspectos de acessibilidade aos serviços, não investigar potenciais inseridos nos territórios áreas de abrangência desses equipamentos de saúde?

Uma dessas potencialidades que se configura também como um estudo geográfico mister no âmbito da área de saúde, corresponde à temática das áreas verdes que, a rigor, beneficiam os cidadãos em seu bem-estar e em sua qualidade de vida.

Será que comunidades mais carentes têm acesso aos serviços de saúde e áreas verdes que porventura possam estar localizadas próximas às suas residências? Nestes espaços livres, públicos, são organizadas atividades práticas de recreação, dinâmicas e encontros que possam proporcionar maior informação e conhecimento sobre temas como: conceitos de cidadania, educação em saúde e educação ambiental? Será que se constituem em espaços funcionais para atividades direcionadas à saúde?

A partir dessas questões, Campello (2008) considera que a evolução do homem ocorre a partir de sua ocupação do solo, que vai ao longo do tempo modificando sua história. Tanto nas áreas urbanas, como nas rurais, os estudos de áreas verdes são imprescindíveis e cada vez mais necessários devido aos graves problemas que prejudicam a vida, advindos da descaracterização do meio ambiente que é resultante do crescimento populacional desordenado das cidades brasileiras e também de outras partes do mundo. ${ }^{4}$

Nesta ótica, por que não identificar como as pessoas entendem a importância desses espaços livres, públicos, inserida nesse território a abrangência dos serviços públicos em saúde. Que contribuições as áreas verdes poderão oferecer à qualidade dos tratamentos desses usuários? Além disso, será que saberiam cobrar do Poder Público e do Estado a inclusão desses espaços públicos próximos aos serviços de saúde?

Esta pesquisa, que é investigativa, tem o desafio de responder a essas questões que, para muitos, poderá se caracterizar por enfoques ideológicos e até mesmo utópicos, porém seus resultados poderão ser utilizados no planejamento e gestão dos serviços de saúde, que teoricamente, pretendem trabalhar de forma preventiva diversas doenças e fomentar a autonomia dos usuários do SUS em seus tratamentos. 


\section{As áreas verdes: alguns conceitos e discussões}

De acordo com Lima et al (1994) as áreas verdes correspondem a uma categoria incluída no conceito de espaço livre onde há predomínio de vegetação arbórea, englobando praças, jardins públicos e parques urbanos. ${ }^{5}$

[...] as áreas verdes englobam locais onde predominam a vegetação arbórea, praças, jardins e parques, e sua distribuição deve servir a toda a população, sem privilegiar qualquer classe social e atingir as necessidades reais e os anseios para o lazer, devendo ainda estar de acordo com sua estrutura e formação (como idade, educação, nível sócio-econômico). ${ }^{6}$

Empregam a expressão "áreas verdes" a diversos tipos de espaços urbanos que podem ser públicos ou particulares e são abertos, acessíveis e relacionados com saúde e recreação. $^{7}$

Mazzei et al consideram que as áreas verdes não são necessariamente voltadas para a recreação e lazer, porém, devem ser dotadas de equipamentos para oferecer opções de lazer e recreação às diferentes faixas etárias, a pequenas distâncias da moradia. ${ }^{8}$

Além dos conceitos de áreas verdes, é fundamental para a compreensão desse estudo, conhecer outras categorias de espaços livres, como os parques urbanos, que apresentam dimensões maiores do que praças e jardins e também apresentam uma função ecológica, estética e de lazer.

Outros autores consideram as praças como espaços livres públicos no cenário urbano, destinados ao lazer e ao convívio da população, acessíveis aos cidadãos e livres de veículos, sejam esses espaços contemplados por áreas verdes ou não. ${ }^{9-10}$

Há ainda aqueles que consideram que "as praças foram reduzidas a estreito oásis de verde, ou a meros espaços de estacionamento, em uma cidade que, com o seu destruidor poder urbano, não dá mais espaço ao prazer de viver em coletividade, fazendo que as pessoas tenham perdido o encanto de estar junto e do confronto direto". ${ }^{11}$

Estudada pela ótica da Geografia, podemos entender a praça não somente como um espaço físico materializado sob a forma de mobiliário urbano, paisagismo e arborização, cujo objetivo seja o de dotar as cidades de "ilhas verdes" para o seu embelezamento. Leva-nos o presente trabalho a uma seara pouco explorada em nosso país, que é a apreensão desses espaços balizados por questões políticas, econômicas, sociais e culturais. Qual seja o entendimento da praça considerando aquele que dela faz uso: o homem. E esse espaço de que estamos tratando pode ser resumido em uma definição muito simples de, como sendo "igual à paisagem mais a vida nela existente; é a sociedade encaixada na paisagem, a vida que palpita conjuntamente com a materialidade". ${ }^{12}$

Silva (2000) complementa como o espaço público foi aos poucos sendo esvaziado, até mesmo abandonado por segmentos mais afortunados da sociedade, devido às suas próprias mudanças de valores, transferindo diversas atividades culturais, sociais, e até econômicas para espaços modernos, como é o caso do Shopping Center. ${ }^{13}$

Em cidades interioranas [...], as praças estão associadas a locais não apenas de encontro, mas também de entretenimento, com a realização de "quermesses" ou outras manifestações das diferentes culturas regionais. Nos bairros periféricos acabam sendo associadas ao ócio e a incipientes atividades de negócio. ${ }^{5}$

De acordo com os objetivos desta pesquisa que pretende investigar as relações entre os serviços de saúde e as áreas verdes na cidade de Mandaguari, Paraná, como locais de sociabilidade aos usuários do SUS, mais especificamente às ações desenvolvidas pelo PSF, faz-se necessário conhecer também as diversas funções estabelecidas pelas áreas verdes, destacando-se sua função social, que contribuirá para as ações desenvolvidas em prol das comunidades locais.

As áreas verdes urbanas podem trazer diversos benefícios aos grupos sociais: controle da poluição do ar e acústica, aumento do conforto ambiental, estabilização de superfícies por meio da fixação do solo pelas raízes das plantas, abrigo à fauna, equilíbrio do índice de umidade do ar, proteção das nascentes e mananciais, valorização visual e ornamental do ambiente, recreação, diversificação da paisagem construída e principalmente, como objetivo deste trabalho, a organização e composição de espaços no desenvolvimento das atividades humanas. Essas funções foram amplamente discutidas por diversos autores. 5,7,14-17

Além desses trabalhos, Henke-Oliveira (1996) salienta que todos esses estudos e elementos contribuem na valorização para a preservação de áreas verdes para o convívio social, a valorização econômica das propriedades e para a formação da memória e do patrimônio cultural. ${ }^{15}$

Vieira (2004) considera que a principal função do sistema de áreas verdes urbanas é a de possibilitar à população momentos de lazer e recreação em contato com a natureza respeitando sua vivência urbana e o contato com outras pessoas. ${ }^{17}$

Henke-Oliveira (1996) argumenta que o "estilo de vida urbano e a estrutura cultural das cidades são elementos associados à tendência ao sedentarismo, aumentando a demanda por áreas verdes e espaços para recreação". ${ }^{15}$

A partir desses estudos, Vieira (2004) considera que as áreas verdes tendem a assumir diferentes papéis na sociedade e, suas funções devem estar inter-relacionadas com o ambiente urbano, como, a função social, cujo papel consiste em ofertar o lazer à população considerando a necessidade de hierarquização (faixas etárias, níveis socioeconômicos e outros). Também a função estética, com a diversidade de paisagens construídas, que contribuem 
para o embelezamento das cidades. A função ecológica, com a melhoria no clima e na qualidade do ar, do solo e da água nas cidades, proporcionando saúde para seus habitantes, devido à vegetação, ao solo não impermeabilizado e à diversidade da fauna. ${ }^{17}$

A função educativa, com ambientes em que possam se desenvolver atividades educativas, que incluam a educação ambiental e sobre a saúde. E a função psicológica com a realização de atividades físicas, de lazer e recreação, ou seja, atividades "antiestresse" e de relaxamento, aproveitando o ambiente em que as pessoas estão diretamente em contato com os elementos naturais das áreas verdes organizadas.

O autor salienta a importância de manutenção e conservação das áreas verdes, para que justamente possam cumprir suas funções, inclusive organizando-as com espécies autóctones.

Com esses pressupostos, conhecer a realidade das condições de saúde e doença do universo de investigação torna-se fundamental, até mesmo para justificar a importância de pesquisar a relação entre os serviços de saúde e a presença das áreas verdes em suas áreas de atuação.

\section{MATERIAIS E MÉTODOS}

Foi elaborado e aplicado um questionário junto às comunidades usuárias das 6 UBS da cidade de Mandaguari, Estado do Paraná, Brasil, no período de abril a dezembro de 2010. As entrevistas foram realizadas nas próprias UBS, normalmente em horários que antecediam as consultas com maior fluxo de pessoas, e também nos grupos focais de saúde organizados pelas Equipes Saúde da Família (ESF) e compostos por usuários dos serviços de saúde a partir de 15 anos de idade: idosos, diabéticos, hipertensos e outros, inclusive organizados em alguns espaços livres, públicos, da cidade.
O questionário objetivou investigar as relações existentes entre as áreas verdes e os serviços de saúde. Para determinar a amostra, adotou-se como base o número total de famílias cadastradas na Estratégia de Saúde da Família (ESF), atualizados através do Sistema de Informação e Atenção Básica - SIAB ${ }^{18}$. Foram respeitados os princípios da resolução 196/96 e o projeto foi aprovado pela Secretaria Municipal de Saúde em 2010.

Com a utilização do programa Pacote Estatístico para as Ciências Sociais, ${ }^{19}$ calculou-se a uma amostra significativa para a população, que representasse as unidades familiares. O número de entrevistas foi proporcional ao total de famílias cadastradas em cada UBS.

Em seguida, foram analisados e avaliados os dados obtidos junto às comunidades referenciadas. A partir desse diagnóstico, foram caracterizadas as áreas verdes, bem como suas influências com relação à qualidade de vida das comunidades usuárias do Sistema Único de Saúde (SUS).

Com os resultados obtidos nas entrevistas, foram determinadas futuras ações de planejamento e monitoramento de áreas verdes, resultando em melhores condições de vida para as comunidades carentes de Mandaguari. Foram respeitados os princípios éticos de pesquisas envolvendo pessoas sendo autorizado o trabalho.

\section{Lazer e importância das áreas verdes para a saúde da população}

A primeira questão analisada refere-se ao tempo disponível em horas semanais dedicadas ao lazer dos usuários das Unidades Básicas de Saúde de Mandaguari (Tabela 1), iniciando a investigação das relações entre as áreas verdes e os serviços públicos de saúde.

Tabela 1 Número de pessoas $\left(\mathrm{N}^{\circ}\right)$ e porcentagem (\%) segundo número de horas semanais para o lazer dos usuários das Unidades Básicas de Saúde de Mandaguari, Paraná.

\begin{tabular}{|c|c|c|c|c|c|c|c|c|c|c|c|c|c|c|c|c|c|c|}
\hline \multirow{3}{*}{$\begin{array}{l}\text { Unidades Básicas } \\
\text { de Saúde }\end{array}$} & \multicolumn{18}{|c|}{ Horas de lazer } \\
\hline & \multicolumn{2}{|c|}{0} & \multicolumn{2}{|c|}{1 a 5} & \multicolumn{2}{|c|}{5 a 10} & \multicolumn{2}{|c|}{10 a 15} & \multicolumn{2}{|c|}{15 a 20} & \multicolumn{2}{|c|}{20 a 25} & \multicolumn{2}{|c|}{25 a 30} & \multicolumn{2}{|c|}{$>30$} & \multicolumn{2}{|c|}{ Total } \\
\hline & № & $\%$ & № & $\%$ & № & $\%$ & № & $\%$ & № & $\%$ & № & $\%$ & № & $\%$ & № & $\%$ & № & $\%$ \\
\hline Jd. Boa Vista & 10 & 18,1 & 28 & 50,9 & 13 & 23,6 & 1 & 1,8 & 0 & 0 & 1 & 1,8 & 2 & 3,6 & 0 & 0 & 55 & 100,0 \\
\hline VI. Vitória & 2 & 11,1 & 10 & 55,5 & 4 & 22,2 & 0 & 0 & 2 & 11,1 & 0 & 0 & 0 & 0 & 0 & 0 & 18 & 100,0 \\
\hline Jd. Esplanada & 21 & 23,5 & 43 & 48,3 & 20 & 22,4 & 3 & 3,3 & 0 & 0 & 0 & 0 & 1 & 1,1 & 1 & 1,1 & 89 & 100,0 \\
\hline Jd. Cristina & 32 & 47,7 & 20 & 29,8 & 9 & 13,4 & 2 & 2,9 & 0 & 0 & 1 & 1,4 & 2 & 2,9 & 1 & 1,4 & 67 & 100,0 \\
\hline Jd. Popular & 41 & 55,4 & 27 & 36,4 & 4 & 5,4 & 0 & 0 & 1 & 1,3 & 1 & 1,3 & 0 & 0 & 0 & 0 & 74 & 100,0 \\
\hline Jd. Progresso & 21 & 35,5 & 21 & 35,5 & 13 & 22,0 & 1 & 1,6 & 0 & 0 & 2 & 3,3 & 0 & 0 & 1 & 1,6 & 59 & 100,0 \\
\hline Total & 127 & 35,0 & 149 & 41,1 & 63 & 17,4 & 7 & 1,9 & 3 & 0,8 & 5 & 1,3 & 5 & 1,3 & 3 & 0,8 & 362 & 100,0 \\
\hline
\end{tabular}

Org.: PEREHOUSKEI, N. A. (2011). 
Será que as pessoas se permitem algumas horas na semana, para passear em um parque, ou mesmo em uma praça pública, ou pelo menos para ficar em contato com o verde? Será que possuem a compreensão da importância deste contato para a prevenção ou a melhoria de sua saúde?

De acordo com os dados coletados, os entrevistados não disponibilizam tempo semanal para se dedicar ao lazer. 0 intervalo mais representativo na amostra foi o período de 1 a 5 horas semanais. Normalmente são as pessoas que trabalham ou estudam, inclusive as mulheres donas de casa.

Estes usuários não destinam tempo algum durante a semana para o lazer, ou seja, envolvem-se em tantas outras atividades que sentem não sobrar nenhum tempo para passear. Nesta variável, podem incluir-se, por exemplo, as mulheres donas de casa, que dedicam praticamente o dia inteiro a essa atividade.

A amostra também demonstra ser relativamente representativa das pessoas que se dedicam ao lazer pelo menos de 5 a 10 horas semanais. Normalmente pessoas que trabalham ou estudam.

Em menores porcentagens, incluem-se as pessoas que destinam mais horas para o lazer, na sequência dos intervalos de 10 a 15 horas, 15 a 20, 20 a 25, 25 a 30, e mais de 30 horas semanais. Nestes intervalos, podem ser incluídas pessoas desempregadas e também aposentadas, principalmente homens.

De um modo geral, os usuários dos serviços de saúde de Mandaguari não têm tempo, ou destinam pouquíssimo tempo durante a semana para se dedicar ao lazer. Esta característica representa pouca dedicação aos problemas de saúde respiratórios ou circulatórios, que ocorrem mais frequentemente em Mandaguari, de acordo com o DATASUS (BRASIL; 2000-2010), bem como pouco tempo de contato com o verde, que tende a transmitir sensações de conforto e bem-estar às pessoas.

A segunda questão analisada refere-se aos lugares de lazer frequentados pelos usuários dos serviços de saúde de Mandaguari (Tabela 2).

Tabela 2. Número de pessoas $\left(\mathrm{N}^{\circ}\right)$ e porcentagem (\%) segundo locais de lazer dos usuários das Unidades Básicas de Saúde de Mandaguari, Paraná.

\begin{tabular}{|c|c|c|c|c|c|c|c|c|c|c|c|c|c|c|c|c|c|c|c|c|c|c|}
\hline \multirow{3}{*}{$\begin{array}{l}\text { Unidade Básica de } \\
\text { Saúde }\end{array}$} & \multicolumn{22}{|c|}{ Locais de lazer* } \\
\hline & \multicolumn{2}{|c|}{ Casa } & \multicolumn{2}{|c|}{ Campo } & \multicolumn{2}{|c|}{$\begin{array}{l}\text { Parente/ } \\
\text { amigo }\end{array}$} & \multicolumn{2}{|c|}{ Cinema } & \multicolumn{2}{|c|}{ Clube } & \multicolumn{2}{|c|}{$\begin{array}{l}\text { Parque da } \\
\text { Pedreira }\end{array}$} & \multicolumn{2}{|c|}{ Pesquei } & \multicolumn{2}{|c|}{ Praça } & \multicolumn{2}{|c|}{ Shopping } & \multicolumn{2}{|c|}{ Outros } & \multicolumn{2}{|c|}{ Total } \\
\hline & № & $\%$ & № & $\%$ & № & $\%$ & № & $\%$ & № & $\%$ & № & $\%$ & № & $\%$ & № & $\%$ & № & $\%$ & № & $\%$ & № & $\%$ \\
\hline Jd. Boa Vista & 1 & 1,1 & 4 & 4,4 & 16 & 17,9 & 0 & 0 & 9 & 10,1 & 23 & 25,8 & 1 & 1,1 & 17 & 19,1 & 0 & 0 & 18 & 20,2 & 89 & 100,0 \\
\hline VI. Vitória & 1 & 3,7 & 0 & 0 & 8 & 29,6 & 0 & 0 & 0 & 0 & 6 & 22,2 & 0 & 0 & 7 & 25,9 & 2 & 7,4 & 3 & 11,1 & 27 & 100,0 \\
\hline Jd. Esplanada & 9 & 8,6 & 2 & 1,9 & 22 & 21,1 & 0 & 0 & 2 & 1,9 & 30 & 28,8 & 1 & 0,9 & 6 & 5,7 & 0 & 0 & 32 & 30,7 & 104 & 100,0 \\
\hline Jd. Cristina & 24 & 29,2 & 0 & 0 & 8 & 9,7 & 1 & 1,2 & 7 & 8,5 & 16 & 19,5 & 0 & 0 & 10 & 12,1 & 0 & 0 & 16 & 19,5 & 82 & 100,0 \\
\hline Jd. Popular & 27 & 32,5 & 2 & 2,4 & 11 & 13,2 & 0 & 0 & 4 & 4,8 & 19 & 22,8 & 1 & 1,2 & 6 & 7,2 & 0 & 0 & 13 & 15,6 & 83 & 100,0 \\
\hline Jd. Progresso & 4 & 5,1 & 5 & 6,4 & 20 & 25,9 & 0 & 0 & 14 & 18,1 & 18 & 23,3 & 1 & 1,2 & 9 & 11,6 & 1 & 1,2 & 5 & 6,4 & 77 & 100,0 \\
\hline Total & 66 & 14,2 & 13 & 2,8 & 85 & 18,3 & 1 & 0,2 & 36 & 7,7 & 112 & 24,2 & 4 & 0,8 & 55 & 11,9 & 3 & 0,6 & 87 & 18,8 & 462 & 100,0 \\
\hline
\end{tabular}

*Alguns entrevistados optaram por mais de 1 alternativa.

Org.: PEREHOUSKEI, N. A. (2011).

Nesta variável, é representativo o percentual de pessoas que frequentam o Parque da Pedreira com 24,2\% dos entrevistados, que é a área verde de referência do município.

Em seguida, a alternativa - "outros" - com 18,8\% de pessoas entrevistadas, que exemplifica diversos locais onde as pessoas procuram alguma forma de lazer, tais como: nas ruas do próprio bairro em que residem para fazer caminhadas; a igreja, que para muitos é sinônimo de lazer; os passeios pelo centro da cidade, onde existem lanchonetes, academia de ginástica e bares, que foram também equipamentos urbanos citados como espaços de lazer pelos entrevistados. E ainda foram consideradas as escolas, as LAN houses e as excursões para outras cidades organizadas por grupos da terceira idade. De acordo com a amostra, a variável - "casa de parente ou amigo" - aspecto que reflete, além das alternativas anteriores, a falta de opções de lazer na cidade de Mandaguari.

As variáveis - "casa" - que representa as pessoas que não saem de casa para frequentar locais de lazer, ou seja, são normalmente pessoas caseiras e procuram seus momentos de lazer dentro da própria casa, como, assistir a um filme, representou $14,2 \%$ do total de pessoas entrevistadas, e "praça" - frequentada normalmente por idosos para jogos e 
momentos de sociabilidade, principalmente na área central do município e outros grupos sociais que frequentam as ATIs para a realização de exercícios físicos, além de participação em eventos culturais e religiosos, representou $11,9 \%$ do total de pessoas entrevistadas.

Também a variável "clube", de acordo com a amostra, normalmente frequentado por idosos nos bailes de terceira idade e outros grupos sociais para prática de esportes, apresentou um percentual de $7,8 \%$.

Em menores porcentagens, ou seja, pouco representativas de acordo com a amostra, encontram-se as variáveis "campo" frequentados normalmente por pessoas que já residem em área rural e têm poucas oportunidades, devido principalmente a suas atividades profissionais, de passear na área urbana do município. E ainda as variáveis: "pesqueiro", "Shopping Center" e "cinema", cujos totais foram mínimos na amostra, sendo os Shoppings frequentados no município de Maringá, já que Mandaguari não possui, e cinema, também associado ao espaço de Shoppings. Os pesqueiros são pouco procurados pela população, já que existem em áreas do entorno do município e também em sua área rural.

Dos 362 entrevistados, foram identificados 462 locais de lazer, o que correspondeu a frequentar 1,3 locais de lazer para cada usuário da UBS, considerando que muitos optaram por mais de uma alternativa.

De acordo com os resultados, pode-se considerar que os usuários dos serviços de saúde de Mandaguari têm como principais atividades de lazer, a ida ao "Parque da Pedreira" e as visitas a parentes e amigos, não costumam frequentar assiduamente outros espaços de lazer e se consideram caseiros. Essas características podem refletir a deficiência em espaços públicos de lazer que sejam atrativos para a comunidade e consequentemente, confirmam o pouco contato com áreas verdes das pessoas, comprometendo inclusive aspectos preventivos da saúde, como os tratamentos relacionados a problemas respiratórios e circulatórios.

Esses resultados corroboram os da variável anterior, que determinam nenhuma ou pouca quantidade de horas dos entrevistados para dedicação ao lazer, bem como o contato com áreas verdes.

A terceira questão apresenta os diversos motivos pelos quais os usuários das Unidades Básicas de Saúde costumam frequentar os espaços de lazer (Tabela 3).

Tabela 3 Número de pessoas $\left(\mathrm{N}^{\circ}\right)$ e porcentagem (\%) segundo os motivos de frequência aos espaços de lazer dos usuários das Unidades Básicas de Saúde de Mandaguari, Paraná.

\begin{tabular}{|c|c|c|c|c|c|c|c|c|c|c|c|c|c|c|c|c|c|c|}
\hline \multirow{3}{*}{$\begin{array}{c}\text { Unidade Básica } \\
\text { de Saúde }\end{array}$} & \multicolumn{18}{|c|}{ Motivos * } \\
\hline & \multicolumn{2}{|c|}{ Não Frequenta } & \multicolumn{2}{|c|}{ Tomar Sol } & \multicolumn{2}{|c|}{ Descansar } & \multicolumn{2}{|c|}{ Caminhar } & \multicolumn{2}{|c|}{$\begin{array}{l}\text { Prática de } \\
\text { Esportes }\end{array}$} & \multicolumn{2}{|c|}{ Ler } & \multicolumn{2}{|c|}{$\begin{array}{l}\text { Levar crianças } \\
\text { para brincar }\end{array}$} & \multicolumn{2}{|c|}{ Outros } & \multicolumn{2}{|c|}{ Total } \\
\hline & № & $\%$ & № & $\%$ & № & $\%$ & № & $\%$ & № & $\%$ & № & $\%$ & № & $\%$ & № & $\%$ & № & $\%$ \\
\hline Jd. Boa Vista & 14 & 20,8 & 0 & 0 & 8 & 11,9 & 13 & 19,4 & 7 & 10,4 & 1 & 1,4 & 5 & 7,4 & 19 & 28,3 & 67 & 100,0 \\
\hline VI. Vitória & 6 & 31,5 & 0 & 0 & 2 & 10,5 & 3 & 15,7 & 0 & 0 & 0 & 0 & 6 & 31,5 & 2 & 10,5 & 19 & 100,0 \\
\hline Jd. Esplanada & 38 & 40,0 & 0 & 0 & 3 & 3,1 & 32 & 33,6 & 4 & 4,2 & 0 & 0 & 17 & 17,8 & 1 & 1,0 & 95 & 100,0 \\
\hline Jd. Cristina & 39 & 55,7 & 1 & 1,4 & 0 & 0 & 17 & 24,2 & 8 & 11,4 & 0 & 0 & 5 & 7,1 & 0 & 0 & 70 & 100,0 \\
\hline Jd. Popular & 42 & 52,5 & 0 & 0 & 6 & 7,5 & 12 & 15,0 & 5 & 6,2 & 1 & 1,2 & 8 & 10,0 & 6 & 7,5 & 80 & 100,0 \\
\hline Jd. Progresso & 21 & 30,8 & 1 & 1,4 & 7 & 10,2 & 18 & 26,4 & 10 & 14,7 & 0 & 0 & 8 & 11,7 & 3 & 4,4 & 68 & 100,0 \\
\hline Total & 160 & 40,1 & 2 & 0,5 & 26 & 6,5 & 95 & 23,8 & 34 & 8,5 & 2 & 0,5 & 49 & 12,2 & 31 & 7,7 & 399 & 100,0 \\
\hline
\end{tabular}

*Alguns entrevistados optaram por mais de uma alternativa.

Org.: PEREHOUSKEI, N. A. (2011).

De acordo com os dados, os entrevistados não costumam frequentar espaços de lazer, com 40,1\% do total de entrevistados, considerando-se pessoas caseiras, que praticamente não saem de casa, por várias razões: não têm tempo porque trabalham; têm problemas de saúde ou cuidam de alguma pessoa doente; não têm costume e outros.

A variável "caminhar", que apresentou uma frequência representativa $(23,8 \%)$ é normalmente realizada no parque referência da cidade que é o "Parque da Pedreira".
Algumas variáveis na amostra apresentaram outros motivos como "levar criança ou filho para brincar", "praticar esportes", "outros" e "descansar".

Na variável - "outros" - ocorrem vários motivos de frequência nestes espaços de sociabilidade, que são: lanchar; simplesmente passear; assistir apresentações culturais ou participar de festas populares; conversar; beber; namorar e pescar.

Os dados também demonstram algumas porcentagens menores nas variáveis "tomar sol" e "ler", que realmente 
foram pouco representativas na amostra. As pessoas não frequentam esses espaços com a intenção de tomar sol, como também não costumam praticar leituras.

Conforme os resultados obtidos, os usuários dos serviços de saúde de Mandaguari apresentaram uma frequência baixa em relação aos espaços de lazer, sendo a atividade mais representativa, a caminhada, normalmente realizada no "Parque da Pedreira" ou nas próprias ruas de seus bairros.

Essa realidade também confirma a falta de opções para o lazer, como também a ausência de contato com áreas verdes.

A quarta questão demonstra os dados sobre o acesso dos usuários dos serviços de saúde às áreas verdes de Mandaguari, e a outras áreas do entorno, ou mesmo de outros municípios (Tabela 4).

Tabela 4 Número de pessoas $\left(\mathrm{N}^{\circ}\right)$ e porcentagem (\%) segundo 0 acesso às áreas verdes dos usuários das Unidades Básicas de Saúde de Mandaguari, Paraná.

\begin{tabular}{lcccccc}
\hline \multirow{2}{*}{$\begin{array}{l}\text { Unidade Básica } \\
\text { de Saúde }\end{array}$} & \multicolumn{2}{c}{ Sim } & \multicolumn{2}{c}{ Não } & \multicolumn{2}{c}{ Total } \\
\cline { 2 - 7 } & № & $\%$ & № & $\%$ & № & $\%$ \\
\hline Jd. Boa Vista & 35 & 63,6 & 20 & 36,3 & 55 & 100,0 \\
Vl. Vitória & 7 & 38,8 & 11 & 61,1 & 18 & 100,0 \\
Jd. Esplanada & 53 & 59,5 & 36 & 40,4 & 89 & 100,0 \\
Jd. Cristina & 34 & 50,7 & 33 & 49,2 & 67 & 100,0 \\
Jd. Popular & 32 & 43,2 & 42 & 56,7 & 74 & 100,0 \\
Jd. Progresso & 30 & 50,8 & 29 & 49,1 & 59 & 100,0 \\
\hline \multicolumn{1}{c}{ Total } & 191 & 52,7 & 171 & 47,2 & 362 & 100,0 \\
\hline
\end{tabular}

Org.: PEREHOUSKEI, N. A. (2011).

Os dados não demonstram muita diferença entre os usuários que frequentam áreas verdes e os que não frequentam; no entanto, ainda prevalecem os usuários que frequentam alguma área verde.

Os entrevistados frequentam o "Parque da Pedreira" de Mandaguari, porém, consideram também outros espaços verdes, chácaras ou sítios, clubes com áreas verdes, fundos de vale, pesqueiros, barragem, o Parque do Ingá localizado na cidade de Maringá e o Parque da Raposa, localizado na cidade de Apucarana.

No entanto, pode-se considerar que muitos entrevistados não os frequentam constantemente, buscando passear nesses espaços apenas esporadicamente.

Em menor porcentagem, no entanto, estão as pessoas que não frequentam espaços verdes, seja por sua atividade profissional, seus compromissos familiares, a falta de costume, ou mesmo a distância para chegar ao Parque da Pedreira que para muitos, é localizado distante de suas residências.
A quinta questão analisa se as áreas verdes contribuem para a melhoria da qualidade de saúde dos usuários (Tabela 5).

Tabela 5. Número de pessoas $\left(\mathrm{N}^{\circ}\right)$ e porcentagem (\%) segundo contribuição das áreas verdes para a saúde dos usuários das Unidades Básicas de Saúde de Mandaguari, Paraná.

\begin{tabular}{lcccccc}
\hline \multirow{2}{*}{$\begin{array}{l}\text { Unidade Básica } \\
\text { de Saúde }\end{array}$} & \multicolumn{2}{c}{ Sim } & \multicolumn{2}{c}{ Não } & \multicolumn{2}{c}{ Total } \\
\cline { 2 - 7 } & № & $\%$ & № & $\%$ & № & $\%$ \\
\hline Jd. Boa Vista & 54 & 98,1 & 1 & 1,8 & 55 & 100,0 \\
Vl. Vitória & 18 & 100,0 & 0 & 0 & 18 & 100,0 \\
Jd. Esplanada & 88 & 98,8 & 1 & 1,1 & 89 & 100,0 \\
Jd. Cristina & 66 & 98,5 & 1 & 1,4 & 67 & 100,0 \\
Jd. Popular & 73 & 98,6 & 1 & 1,3 & 74 & 100,0 \\
Jd. Progresso & 58 & 98,3 & 1 & 1,6 & 59 & 100,0 \\
\hline \multicolumn{1}{c}{ Total } & 357 & 98,6 & 5 & 1,3 & 362 & 100,0 \\
\hline
\end{tabular}

Org.: PEREHOUSKEI, N. A. (2011).

De acordo com os dados, a porcentagem de pessoas que consideram alguma contribuição das áreas verdes para a saúde foi extremamente representativa com $98,6 \%$ do total de entrevistados, com diversos aspectos enfocados, tais como: as áreas verdes oferecem ar puro, limpo e saudável; deixam as pessoas com alto astral; são áreas menos poluídas; as pessoas se sentem melhor em contato com as áreas verdes; ajudam a respirar melhor; ótimo espaço para praticar esportes; a harmonia das cores da natureza faz muito bem à saúde; faz a pessoa se sentir livre; é uma terapia para a cabeça; ajuda a melhorar a depressão; contemplar a paisagem, a beleza do verde faz muito bem; o contato com o verde é muito saudável; é muito bom aproveitar a sombra das árvores para descansar; espaços para conversar, brincar e relaxar; diminui o estresse; espaços para se sentir mais tranquilo e à vontade; para praticar exercícios físicos; é sinônimo de vida; é um ambiente saudável; faz a pessoa se sentir bem em apoiar e contribuir para a conservação dessas áreas; purificar os pulmões; ótimo para passear; espaço para acompanhamento médico (receber orientações); divertir-se com a fauna e contemplar a beleza da flora; é um ambiente necessário para viver bem; é o que determina a saúde; o contato com o verde desperta a consciência ambiental; ajuda a combater doenças; descontrair; é um ambiente calmo e transmite paz; ambiente bonito e conservado; espaço para sociabilização e recreação; ótimo lugar para esquecer os problemas; o cheiro da natureza faz muito bem; é uma necessidade para o organismo humano; é um lugar ótimo para levar as crianças para passear; nestes espaços, as pessoas se sentem mais felizes, alegres; o clima (tempo) é mais gostoso; ajuda no controle da umidade e das chuvas, no equilíbrio ambiental; ameniza o calor; é um ambiente mais gostoso; ajuda a arejar; são áreas sem poluição sonora; são ótimas para descarregar a energia; o contato com as áreas verdes ajuda a dormir melhor e 
contribui como apoio psicológico.

A porcentagem de pessoas que não consideram importantes as áreas verdes para a saúde foi mínima, normalmente pessoas desinformadas, que não conseguem associar os temas ou simplesmente não souberam responder a questão, de acordo com as respostas obtidas pelos entrevistados em trabalho de campo.

Conforme os resultados, de acordo com a amostra, as pessoas entrevistadas têm consciência da importância das áreas verdes para a saúde, relatadas pela maioria dos usuários de todas as UBS.

A sexta questão demonstra a opinião dos entrevistados com relação à utilização de espaços livres públicos, como praças e parques, pelo PSF para alguma atividade em saúde (Tabela 6).

Tabela 6. Número de pessoas $\left(\mathrm{N}^{\circ}\right)$ e porcentagem (\%) segundo espaços públicos utilizados para as atividades das Equipes Saúde da Família de Mandaguari, Paraná. (2010).

\begin{tabular}{lcccccc}
\hline \multirow{2}{*}{$\begin{array}{l}\text { Unidade Básica } \\
\text { de Saúde }\end{array}$} & \multicolumn{2}{c}{ Sim } & \multicolumn{2}{c}{ Não } & \multicolumn{2}{c}{ Total } \\
\cline { 2 - 7 } & № & $\%$ & № & № & $\%$ & № \\
\hline Jd. Boa Vista & 54 & 98,1 & 1 & 1,8 & 55 & 100,0 \\
Vl. Vitória & 18 & 100,0 & 0 & 0 & 18 & 100,0 \\
Jd. Esplanada & 87 & 97,7 & 2 & 2,2 & 89 & 100,0 \\
Jd. Cristina & 61 & 91,0 & 6 & 8,9 & 67 & 100,0 \\
Jd. Popular & 66 & 89,1 & 8 & 10,8 & 74 & 100,0 \\
Jd. Progresso & 58 & 98,3 & 1 & 1,6 & 59 & 100,0 \\
\hline \multicolumn{1}{c}{ Total } & 344 & 95,0 & 18 & 4,9 & 362 & 100,0 \\
\hline
\end{tabular}

Org.: PEREHOUSKEI, N. A. (2011).

De acordo com os dados, os entrevistados acreditam ser fundamental a utilização desses espaços para as atividades com $95 \%$ do total de entrevistados e expressam várias possibilidades, entre as quais: organização de atividades de conscientização em Educação Ambiental (conservação de áreas verdes); atividades físicas, com alongamentos, caminhadas e exercícios de relaxamento; atividades de lazer: piquenique, jogos, recreação (gincanas); passeios e excursões para todas as faixas etárias; organização de palestras nestes espaços com orientações para a saúde, meio ambiente e educação no trânsito; grupos de saúde, inclusive com acompanhamento médico e de enfermagem; organização de grupos para plantio de árvores (reflorestamento de áreas); grupos para a limpeza das áreas verdes; organização de eventos, como "Caminhadas Ecológicas" e "Tardes de Lazer"; cultivo e oferta de ervas medicinais; promoção de momentos de reflexão e organização de pescarias.

A porcentagem de entrevistados que não consideram importante a utilização desses espaços para as atividades da saúde foi mínima, normalmente por não considerarem importante, não terem tempo para participar, não associar os temas ou mesmo serem indiferentes a essa prática, de acordo com as respostas obtidas em trabalho de campo.

Os usuários das UBS Jardim Cristina e Jardim Progresso foram os que apresentaram as maiores porcentagens de entrevistados, em relação às outras UBS, que não acreditam na organização das áreas verdes com o intuito de serem utilizadas pelo PSF em atividades de saúde, representando respectivamente $8,9 \%$ e $10,8 \%$ do total de entrevistados.

Alguns entrevistados consideram que a ESF não dispõe de tempo para se dedicar a essas atividades, pois já é sobrecarregada de trabalho na própria UBS, devendo ser organizada uma equipe específica para desenvolver essas atividades por meio da prefeitura, ou mesmo, por membros ou por lideranças da Comunidade.

Conforme os resultados obtidos, pode-se considerar que os usuários dos serviços de saúde acreditam que a equipe da UBS, pode e deve organizar atividades em saúde, aproveitando as áreas verdes, para a melhoria de sua qualidade de vida.

A sétima e última questão analisada refere-se à responsabilidade pela manutenção, conservação e limpeza dos espaços livres públicos (Tabela 7).

Tabela 7. Número de Pessoas ( $\left.\mathrm{N}^{\circ}\right)$ e porcentagem (\%) segundo opinião sobre a responsabilidade com relação aos espaços públicos dos usuários das Unidades Básicas de Saúde de Mandaguari, Paraná.

\begin{tabular}{|c|c|c|c|c|c|c|c|c|}
\hline \multirow{2}{*}{$\begin{array}{l}\text { Unidade Básica } \\
\text { de Saúde }\end{array}$} & \multicolumn{2}{|c|}{ População } & \multicolumn{2}{|c|}{ Prefeitura } & \multicolumn{2}{|c|}{ Ambos } & \multicolumn{2}{|c|}{ Total } \\
\hline & № & $\%$ & № & $\%$ & № & $\%$ & № & $\%$ \\
\hline Jd. Boa Vista & 8 & 14,5 & 3 & 5,4 & 44 & 80,0 & 55 & 100,0 \\
\hline VI. Vitória & 2 & 11,1 & 1 & 5,5 & 15 & 83,3 & 18 & 100,0 \\
\hline Jd. Esplanada & 8 & 8,9 & 4 & 4,4 & 77 & 86,5 & 89 & 100,0 \\
\hline Jd. Cristina & 3 & 4,4 & 9 & 13,4 & 55 & 82,0 & 67 & 100,0 \\
\hline Jd. Popular & 6 & 8,1 & 1 & 1,3 & 67 & 90,5 & 74 & 100,0 \\
\hline Jd. Progresso & 0 & 0 & 0 & 0 & 59 & 100,0 & 59 & 100,0 \\
\hline Total & 27 & 7,4 & 18 & 4,9 & 317 & 87,5 & 362 & 100,0 \\
\hline
\end{tabular}

Org.: PEREHOUSKEI, N. A. (2011).

Dos entrevistados $87,5 \%$ consideram que esta responsabilidade deve ser conjugada entre o Poder Público, representado pela Prefeitura do município, juntamente com a população, que garante sua representatividade por meio de organizações de bairro (associações) ou Organizações Não Governamentais (ONGs).

As porcentagens que consideram a responsabilidade apenas do Poder Público, ou apenas da população foram mínimas; no entanto, mesmo assim, consideram a população ainda mais responsável.

Em todas as unidades de saúde ocorrem porcentagens 
maiores para a responsabilidade da população, com exceção da UBS Jardim Cristina. Na UBS Jardim Progresso não ocorrem porcentagens apenas para a responsabilidade do Poder Público ou da população; a amostra demonstra que ambos são responsáveis pelas áreas verdes.

Mandaguari possui associações direcionadas ao meio ambiente, principalmente ligadas ao setor agrícola de agronegócios (agro business), e muitas organizadas como cooperativas, sendo as principais: Associação Rural de Mandaguari, Associação dos Produtores de Cana do Norte Paranaense e Associação Industrial, Comercial e Agrícola de Mandaguari, não havendo preocupação com a pequena produção familiar.

Conforme os resultados obtidos, considera-se que os usuários dos serviços de saúde acreditam que ações conjugadas entre o Poder Público e a sociedade civil, possam trazer bons resultados na manutenção e conservação de áreas verdes, e também a criação de novos espaços livres públicos de uso coletivo, devido principalmente à carência de áreas verdes e opções de sociabilidade existentes no município de Mandaguari, que atendam de forma eficaz às camadas da população menos favorecidas.

Esta preocupação deve ser constante no planejamento de áreas verdes, bem como das propostas de ações preventivas nos serviços de saúde, que devem contar com esses espaços públicos para a melhoria da qualidade de vida dos usuários do SUS.

O conceito de território na área de saúde deve ser ampliado, considerando também a potencialidade das áreas verdes urbanas, como equipamentos de apoio às ações de prevenção aos serviços públicos de saúde, devido principalmente à gama de benefícios que podem oferecer aos usuários na prevenção e no avanço de seus tratamentos, e, consequentemente, na melhoria de sua qualidade de vida.

\section{CONSIDERAÇÕES FINAIS}

Com a análise das relações existentes entre as áreas verdes e a saúde pode-se concluir que os entrevistados dedicam pouco ou nenhum tempo, durante a semana, para o lazer, devido principalmente às suas atividades profissionais, problemas de saúde, acompanhamento de familiares doentes, ausência de espaços públicos para percorrer e outros.

De um modo geral, os usuários dos serviços de saúde de Mandaguari têm apenas como principal alternativa para o lazer, o "Parque da Pedreira" e costumam visitar parentes e amigos. Existem pessoas que não costumam frequentar espaços de lazer e se consideram caseiras. Essas características refletem a deficiência de espaços públicos de lazer que sejam atrativos para a Comunidade e, consequentemente, confirmam o pouco contato com áreas verdes das pessoas, comprometendo inclusive aspectos preventivos da saúde, bem como os tratamentos relacionados a problemas respiratórios e circulatórios. Dos entrevistados que não costumam frequentar espaços de lazer, considerando-se pessoas caseiras que praticamente não saem de casa, ocorrem algumas razões para tal dinâmica: não têm muito tempo porque trabalham; têm problemas de saúde ou cuidam de alguma pessoa doente; não têm o hábito e outras.

Os entrevistados frequentam o "Parque da Pedreira" de Mandaguari, porém, consideram outros espaços verdes, como chácaras ou sítios, clubes com áreas verdes, fundos de vale, pesqueiros, barragem e o Parque do Ingá localizado na cidade de Maringá, e o Parque da Raposa na cidade de Apucarana. Pode-se considerar que muitos dos entrevistados não os frequentam constantemente, buscando passear nesses espaços apenas esporadicamente.

Além das contribuições das áreas verdes para a saúde encontradas nas literaturas, ocorreram diversas opiniões emitidas pelos usuários dos serviços de saúde, que vêm confirmar os benefícios que essas áreas proporcionam a melhoria da qualidade de vida da população, quais sejam: as áreas verdes oferecem ar puro, limpo e saudável; deixam as pessoas com alto astral; são áreas menos poluídas; as pessoas se sentem melhor em contato com as áreas verdes; ajudam a respirar melhor; ótimo espaço para praticar esportes; a harmonia das cores da natureza faz bem à saúde; faz a pessoa se sentir livre, e outras.

Os entrevistados também acreditam ser fundamental a utilização desses espaços para as atividades em saúde e expressam várias possibilidades, entre as quais: organização de atividades de conscientização em Educação Ambiental (conservação de áreas verdes); atividades físicas, com alongamentos, caminhadas e exercícios de relaxamento; atividades de lazer e outras.

Em relação à responsabilidade pela organização e manutenção das áreas verdes urbanas, os entrevistados consideram que esta deve ser conjugada entre o Poder Público, representado pela Prefeitura do município, juntamente com a população, que garante sua representatividade por meio de organizações de bairro (associações) ou Organizações Não Governamentais (ONGs).

A contribuição da presente pesquisa para o planejamento das áreas verdes articuladas com o planejamento dos serviços de saúde na perspectiva territorial é única, pois se concretiza como uma proposta de organização que busca principalmente, conhecer a realidade local emitida pelos atores sociais envolvidos no processo. Esta característica constitui o grande diferencial das propostas atuais de planejamento que são normalmente ditadas por profissionais de gabinete, que nada conhecem sobre a realidade local.

A proposta deste trabalho é, primeiramente, incluir como política pública o desenvolvimento de projetos que articulem a organização e a manutenção de áreas verdes 
com o objetivo de auxiliar, na qualidade de espaço social, as atividades desenvolvidas pelo setor de saúde.

Como segunda proposta, promover a organização de um setor de planejamento nas prefeituras que trabalhe diretamente com a divisão de áreas de abrangência das UBS, acompanhando suas dinâmicas e transformações, aproveitando suas potencialidades, incluindo os benefícios oferecidos pelas áreas verdes urbanas, e promovendo atividades que auxiliem nos tratamentos e na sociabilidade dos grupos de saúde, com vistas a melhoria de qualidade de vida dos usuários do SUS numa perspectiva de coletividade, sempre com o apoio e a participação dos atores sociais envolvidos, seja por meio de lideranças de bairros ou por meio da sociedade civil organizada, que deve ter seu papel de formadora de opinião garantido nas relações sociais estabelecidas nos espaços geográficos.

\section{REFERÊNCIAS}

1. Ministério da Saúde (Brasil), Conselho Nacional dos Secretários de Saúde. Pacto pela Saúde [CD-ROM]. Brasília: CONASS, 2006.

2. Perehouskei NA. Estudo das áreas de abrangência das Unidades Básicas de Saúde do município de Maringá [MONOGRAFIA]. Maringá: Universidade Estadual de Maringá; 2001.

3. Perehouskei NA, Benaduce GMC. Abrangência das unidades básicas de saúde: a percepção da comunidade nos bairros universo e pinheiros no município de Maringá-Pr. 2001 a 2005. Espaço \& Geografia[Internet]. 2007 acesso 2014 abr 24]; 10(1): 219-267. Disponível em: http://www. Isie.unb.br/espacoegeografia/index.php/espacoegeografia/article/ view/67/66

4. Campello CC. Áreas verdes: índices que sustentam a vida. São Paulo: MPSP, 2008. [acesso em 2014 abr 20]. Disponível em: http://www. mpsp.mp.br/portal/page/portal/cao_urbanismo_e_meio_ambiente/ material_apoio/mamodelos/mod_urbanismo/mod_urb_pecas/mod_ urb_pecas_parecer/\%C3\%81REAS-VERDES-\%C3\%8DNDICES-QUESUSTENTAM-A-VIDA.pdf

5. Lima AMLP, Cavalheiro F, Nucci JC, Sousa MALB, Fialho NO, Del Picchia PCD. Problemas de utilização na concentração de termos como espaços livres, áreas verdes e correlatas. In: Congresso Brasileiro de Arborização Urbana 2, 1994; São Luís: Imprensa EMATER/MA, 1994.

6. Morero AM, Santos, RF, Fidalgo, ECC. Planejamento ambiental de áreas verdes: estudo de caso de Campinas-SP. Rev. Inst Flor [Internet]. 2007 jun [acesso 2014 abr 24]; 19(1): 19-30. Acesso em: http://www. iflorestal.sp.gov.br/publicacoes/revista_if/rev19-1pdf/19-30.pdf.

7. Toledo FS, Santos DG. Espaços livres de construção. Revsbau [Internet] 2008 [acesso 2014 abr 24]; 3(1): 73-91. Disponível em: http://www. revsbau.esalq.usp.br/artigos_revisao/revisao02.pdf.

8. Mazzei K, Colsesanti MTM, Santos DG. Áreas verdes urbanas, espaços livres para o lazer. Sociedade \& Natureza [Internet]. 2007 jun [acesso 2014 abr 24]; 19(1): 33-43. Disponível em: http://www.seer.ufu.br/ index.php/sociedadenatureza/article/view/9350/5730.
9. De Angelis BLD. A praça no contexto das cidades: o caso de Maringá-PR [Tese]. São Paulo: Universidade de São Paulo, 2000.

10. Robba F, Macedo SS. Praças brasileiras. São Paulo: Edusp, 2002.

11. Loboda CR, De Angelis BLD. Áreas verdes urbanas: conceitos, usos e funções. Ambiência [Internet]. 2005 [acesso 2014 abr 24], 1(1): 125-139. Disponível em: http://revistas.unicentro.br/index.php/ ambiencia/article/viewFile/157/185.

12. Santos M. Espaço \& método. São Paulo: Nobel, 1988.

13. Silva MAV. A Praça do Ferreira: seu uso e apropriação. [Dissertação]. São Paulo: Universidade de São Paulo; 2000.

14. Cavalheiro F, Del Picchia PCD. Áreas verdes: conceitos, objetivos e diretrizes para o planejamento. In: Anais do 1 을 Congresso Brasileiro sobre Arborização Urbana, 1992; Vitória. Editora Vitória; 1992. p. 2938.

15. Henke-Oliveira C. Planejamento ambiental na cidade de São Carlos com ênfase nas áreas públicas e áreas verdes: diagnóstico e proposta [Dissertação]. São Carlos: Universidade Federal de São Carlos; 1996.

16. Nucci JC, Moura AR. Análise da cobertura vegetal do bairro de Santa Felicidade, Curitiba-PR. In: Anais do 11 Simpósio Brasileiro de Geografia Aplicada, 2005; São Paulo. São Paulo: USP; 2005. p. 328-337.

17. Vieira, PBH. Uma visão geográfica das áreas verdes de FlorianópolisSC: estudo de caso do Parque Ecológico do Córrego Grande (PECG) [Monografia]. Florianópolis: Universidade Federal de Santa Catarina; 2004.

18. Prefeitura do Município de Mandaguari (Brasil). Dados sobre a cidade de Mandaguari. [Internet] Mandaguari; 2009. [acesso 2009 fev 20]. Disponível em: http://www.mandaguari.pr.gov.br

19. Pacote estatístico para ciências sociais (SPSS). In: RIBEIRO, E. A. Análise de dados quantitativos para Ciências Humanas: abordagem introdutória com uso do SPSS. Curso de extensão. Maringá: Universidade Estadual de Maringá. Departamento de Ciências Sociais, 2010. Programa digital.

Como citar este artigo / How to cite this article:

Perehouskei NA, De Angelis BLD. A influência das áreas verdes nos serviços públicos de saúde na cidade de Mandaguari, Paraná, Brasil. J Health Biol Sci. 2014 Abr-Jun; 2(2):74-83. 